\title{
Efeito alelopático de Andira humilis Mart. ex Benth na germinação e no crescimento de Lactuca sativa L. e Raphanus sativus $\mathbf{L}$.
}

\author{
Fernando Periotto ${ }^{1,3}$, Sonia Cristina Juliano Gualtieri de Andrade Perez ${ }^{2,3}$ e Maria Inês Salgueiro Lima ${ }^{2}$
}

\author{
Recebido em 16/06/2003. Aceito em 07/11/2003
}

\begin{abstract}
RESUMO - (Efeito alelopático de Andira humilis Mart. ex Benth na germinação e no crescimento de Lactuca sativa L. e Raphanus sativus L.). Neste trabalho, objetivou-se avaliar o efeito alelopático de caules e folhas de Andira humilis na germinação de sementes e no crescimento de plântulas de rabanete e alface. Para os experimentos de germinação foram preparados extratos aquosos de caules e folhas de A. humilis nas concentrações de $0,4,8,12$ e $16 \%(\mathrm{p} / \mathrm{v})$. Foram realizadas quatro réplicas de trinta sementes de alface ou de rabanete, distribuídas em placas de Petri forradas com papel-filtro umedecido com $5 \mathrm{~mL}$ dos extratos, mantidas a $27^{\circ} \mathrm{C}$ e na ausência de luz. As contagens das sementes germinadas foram realizadas a cada $12 \mathrm{~h}$, calculando-se a percentagem e a velocidade de germinação. Extratos de caules e folhas reduziram significativamente a velocidade e a percentagem de germinação, em relação ao grupo controle. Os experimentos de crescimento foram realizados com quatro réplicas de oito sementes germinadas de alface ou de rabanete, a $27^{\circ} \mathrm{C}$, na ausência de luz e em papel-filtro como substrato, sendo avaliadas as concentrações 0,4 e $12 \%$ (p/v). Plântulas de alface e rabanete sofreram inibição significativa em seus comprimentos, pelos extratos de folhas. Extratos de caules a 4 e $12 \%$ (p/v) não causaram inibição do crescimento em rabanete. A interferência dos extratos na germinação e no crescimento em alface e rabanete foi desassociada de qualquer efeito do potencial osmótico e do $\mathrm{pH}$, indicando, portanto, atividade alelopática.
\end{abstract}

Plavras-chave: alelopatia, Andira humilis, germinação, crescimento

\begin{abstract}
Allelopathic effect of Andira humilis Mart. ex Benth in the germination and growth of Lactuca sativa L. and Raphanus sativus L.). The objective of this study was to evaluate allelopathic effects of stems and leaves of Andira humilis in the germination and growth of radish and lettuce. For the germination's experiments, aqueous extracts of stems and leaves of A. humilis in the concentrations of $0,4,8,12 \mathrm{e} 16 \%(\mathrm{w} / \mathrm{v})$ were done. Were employed four replicates of thirty seeds of lettuce and radish. The seeds were distributed in Petri dishes with filter paper moistened with $5 \mathrm{~mL}$ of the extracts. The experiments were conducted at $27^{\circ} \mathrm{C}$ in light absence. The counting of germinated seeds was done each $12 \mathrm{~h}$, calculating the percentage and germination rate. The extracts at 8,12 and $16 \%$ (w/v) reduced lettuce and radish germination rate, extracts of stems at $100 \%$ reduced the percentage of germination. Four replicates of eight germinated seeds of lettuce or radish were employed in the growth experiments conducted at $27^{\circ} \mathrm{C}$ in the absence of light and having filter paper as substracts moistened with concentrations of 0,4 e $12 \%$ (w/v). Lettuce and radish seedlings suffered significant inhibition in length, when using leaves extracts. Only 4 e 12\% (w/v) stems extracts didn't caused growth inhibition in radish. The interference of extracts in germination and growth of lettuce and radish was disassociated of any $\mathrm{pH}$ and osmotic potential, indicating allelopathic activity.
\end{abstract}

Key words: allelopathy, Andira humilis, germination, growth

\section{Introdução}

Alelopatia é a capacidade dos vegetais superiores ou inferiores produzirem substâncias químicas que, quando liberadas no ambiente, influenciam de forma favorável ou desfavorável o desenvolvimento de outros organismos (Rice 1984). Esse fenômeno envolve complexa cadeia de comunicação química entre as espécies vegetais (Harborne 1993).

Os efeitos alelopáticos são mediados através de substâncias químicas pertencentes a diferentes categorias de compostos, tais como fenóis, terpenos, alcalóides, poliacetilenos, ácidos graxos, peptídeos, entre outros. Essas substâncias químicas estão presentes em diferentes órgãos, incluindo folhas, flores, frutos e gemas de muitas espécies vegetais (Miró et al. 1998; Delachiave et al. 1999).

A maioria destas substâncias provém do metabolismo secundário vegetal e, na evolução das plantas, representaram alguma vantagem contra a ação de microrganismos, vírus, insetos e outros patógenos ou predadores, seja inibindo a ação destes, ou estimulando o crescimento ou desenvolvimento das plantas (Waller 1999).

\footnotetext{
1 Programa de Pós-Graduação em Ecologia e Recursos Naturais, Universidade Federal de São Carlos, Via Washington Luiz, Km 235, C. Postal 676, CEP 13565-905, São Carlos, SP, Brasil

2 Departamento de Botânica - UFSCar (dsp@power.ufscar.br; ines@power.ufscar.br)

3 Apoio $\mathrm{CNPq}$

4 Autor para correspondência: periotto.f@zipmail.com.br
} 
O efeito visível dos aleloquímicos sobre as plantas é somente uma sinalização secundária de mudanças anteriores. Portanto, os efeitos desses compostos sobre a germinação e/ou desenvolvimento da planta são manifestações secundárias de efeitos ocorridos inicialmente ao nível molecular e celular. Ainda há relativamente poucas informações sobre estes mecanismos (Ferreira \& Aquila 2000).

Einhellig (1995) relatou vários mecanismos de ação desempenhados pelos agentes aleloquímicos nos vegetais, os quais atuam nos efeitos da atividade hormonal, na biossíntese e distribuição de metabólitos, na morfologia celular, na fotossíntese, ocasionando efeitos em plantas intactas, células isoladas, cloroplastos e clorofilas, na respiração, atuando nas mitocôndrias e em processos associados à membrana celular, causando acúmulo de íons e interferência nas relações hídricas.

Outros aspectos importantes da alelopatia, além dos fatores que afetam sua produção e liberação no ambiente, incluem sua absorção e translocação no organismo receptor, enfim, sua efetividade como aleloquímico; uma vez esclarecidos, trarão importante contribuição para a compreensão deste fenômeno (Ferreira \& Aquila 2000).

Para o efeito alelopático ser constatado, o procedimento inicial consiste na técnica do bioensaio, empregando-se material biológico como indicador da substância em estudo (Inderjit \& Dakshini 1995).

Na natureza, alelopatia pode ser confundida com o processo de competição. Rice (1979) aponta que o efeito alelopático consiste na liberação no ambiente de um composto químico pela planta, ao passo que competição é a remoção ou redução de um fator ambiental, tal como água, luz, minerais, etc. Há exemplos claros que alelopatia e competição são fenômenos distintos na natureza, embora possam estar bastante interrelacionados (Ferreira \& Aquila 2000).

Além da drástica redução das áreas naturais de cerrado, pouco se sabe sobre os efeitos alelopáticos de plantas nativas na germinação de sementes e no desenvolvimento de plântulas de outras espécies. Nota-se, portanto, a grande importância da realização de pesquisas nesse campo, para se conhecer os mecanismos de ação, produção e decomposição de compostos alelopáticos, assim como o ciclo desses compostos nas plantas.

Andira humilis Mart. ex Benth. (Leguminosae, Papilionoideae) é uma espécie que ocorre em cerrado, cerrado ralo e cerrado rupestre, distribuindo-se pelo Distrito Federal, Goiás, Mato Grosso, Mato Grosso do Sul, Minas Gerais, Paraíba, Pernambuco e São Paulo.
De hábito subarbustivo a arbustivo, atinge até um metro de altura (Almeida et al. 1998). A multiplicação dessa espécie conhecida popularmente como Angelimrasteiro, Angelim-do-campo ou Mata-barata no campo ocorre predominantemente pela regeneração vegetativa por meio de sóboles (Ferri 1969).

Handro (1969), estudando aspectos das plântulas e das unidades de dispersão de Andira humilis, observou que suas populações nos cerrados não estão limitadas à multiplicação vegetativa, embora tal comportamento deva ser o mais freqüente, pois não existem impedimentos essenciais intrínsecos para a reprodução sexuada da mesma. Entretanto, é possível que a ocorrência de germinação em condições naturais se dê apenas em alguns anos, nos quais haveria coincidência de sucessivas circunstâncias favoráveis.

Observações de campo permitiram levantar a hipótese de que poderia haver efeito alelopático de Andira humilis sobre outras espécies vegetais, uma vez que esta espécie forma grupamentos homogêneos e prejudica o estabelecimento de outras.

Desse modo, objetivou-se, no presente trabalho, avaliar o efeito alelopático dos extratos aquosos de Andira humilis na germinação de sementes e no crescimento de plântulas de alface (Lactuca sativa $\mathrm{L}$.) e de rabanete (Raphanus sativus L.).

\section{Material e métodos}

Os experimentos foram conduzidos nos laboratórios de Ecofisiologia de Sementes e de Ecologia Vegetal do Departamento de Botânica da Universidade Federal de São Carlos (UFSCar). O material vegetal foi coletado em áreas de vegetação de cerrado, pertencentes ao câmpus da UFSCar, localizado no município de São Carlos, SP.

Plantas adultas de Andira humilis Mart. ex Benth foram coletadas na segunda quinzena de fevereiro/2002. A retirada das porções subterrâneas (caules) e aéreas (folhas) ocorreram com o auxílio de enxadão e tesoura de poda, respectivamente. Este material foi mantido em "freezer", a $-10^{\circ} \mathrm{C}$, até o momento da extração dos compostos.

Para a realização dos bioensaios foram utilizadas sementes de Raphanus sativus L. cv. "Crimson gigante" (rabanete) e de Lactuca sativa L. cv. "Grand rapidis" (alface). Foram efetuados testes preliminares em laboratório para verificação da viabilidade e do vigor da germinação das sementes.

Os extratos utilizados nos bioensaios foram preparados com caules e folhas adultas de Andira 
humilis. O material vegetal foi triturado em liqüidificador industrial, na proporção de $33,3 \mathrm{~g}$ em $200 \mathrm{~mL}$ de água destilada, ou seja, $16 \%$ (p/v). A trituração foi realizada durante três minutos, em temperatura de ambiente de laboratório $\left(25^{\circ} \mathrm{C}\right)$, seguida de filtração e posterior obtenção do extrato bruto, $16 \%$ $(\mathrm{p} / \mathrm{v})$, considerado como o de maior concentração. A partir desse extrato bruto, por diluição em água destilada, foram elaborados os demais extratos: $12 \%$, $8 \%$ e $4 \%(\mathrm{p} / \mathrm{v})$.

Os testes de germinação foram realizados em placas de Petri esterilizadas de $9 \mathrm{~cm}$ diâm., contendo duas folhas de papel-filtro umedecidas com $5 \mathrm{~mL}$ de extrato aquoso, de modo a que a solução estivesse bem distribuída. Foram utilizadas quatro réplicas simultâneas de trinta sementes de alface e de rabanete, mantidas em câmaras tipo BOD (modelo NT 708-AT - Nova Técnica) em temperatura constante igual a $27^{\circ} \mathrm{C}$ e na ausência de luz. Testaram-se todas as concentrações do extrato e, como controle, utilizou-se água destilada para umedecer o papel-filtro.

Foi medido o $\mathrm{pH}(\mathrm{pH} / \mathrm{mVMeter}$ UB-10) e a concentração molar (Automatic Osmometer Model $5004 \mu$ Osmette $^{\mathrm{TM}}$ Precision Systems INC.), calculando-se posteriormente o potencial osmótico dos extratos de caules e folhas de maior concentração, $16 \%$ (p/v), a partir da expressão citada por Vilela et al. (1991). Foram preparadas soluções com polietilenoglicol 6000 (PEG 6000) (Vilela et al. 1991), nas concentrações equivalentes às soluções dos extratos e, posteriormente, nessas soluções, foram feitos testes de germinação de sementes e crescimento de plântulas em alface e em rabanete. $\mathrm{O}$ rendimento dos mesmos também foi calculado, onde $5 \mathrm{~mL}$ do extrato $16 \%$ (p/v) foram aplicados em papel-filtro e evaporados à secura no interior de uma capela em ventilação por $24 \mathrm{~h}$, em temperatura ambiente $\left(28^{\circ} \mathrm{C}\right)$, pesando-se em balança analítica o resíduo impregnado, descontando-se o peso inicial deste papel-filtro seco.

As semente recebera luz por ocasião das leituras de germinação, que foram realizadas em intervalos de $12 \mathrm{~h}$, durante 7 dias, considerando-se sementes germinadas as que apresentaram $2 \mathrm{~mm}$ de protrusão de radícula (Brasil 1992). Os cálculos para os parâmetros de germinação seguiram expressões citadas em Labouriau \& Valadares (1976).

O delineamento experimental do teste de germinação foi inteiramente casualizado, com quatro réplicas de 30 sementes de alface ou de rabanete. As análises estatísticas foram realizadas com auxílio do Softwear Prism - 1999 e GrafPad InStat, utilizando-se o teste de Tukey a 5\% de probabilidade.

$\mathrm{Na}$ análise de crescimento das plântulas foram utilizadas as concentrações de extrato 0,4 e $12 \%(\mathrm{p} / \mathrm{v})$. As sementes, previamente germinadas em água, apresentando emissão de raiz primária de cerca de $2 \mathrm{~mm}$ de comprimento, foram postas em placas de Petri de $9 \mathrm{~cm}$ diâm., contendo papel-filtro e vedadas. Foram utilizados $5 \mathrm{~mL}$ de extrato por placa, e, como controle, utilizou-se água destilada para umedecer o papel-filtro. $\mathrm{O}$ experimento foi conduzido em câmaras tipo BOD (modelo NT 708-AT - Nova Técnica), a $27^{\circ} \mathrm{C}$ e na ausência de luz.

As avaliações para análise de crescimento foram feitas medindo-se o comprimento de plântulas inteiras (distância do ápice da plântula até o ápice meristemático do sistema radicular) de Lactuca sativa e Raphanus sativus, com 10 dias de idade. Para a obtenção dos parâmetros biométricos, foram feitas quatro réplicas com oito unidades de plântulas, com o auxílio de paquímetro digital, seguindo-se especificações de Benincasa (1988) modificado.

\section{Resultados e discussão}

Observou-se nos testes de germinação de sementes de alface que os extratos de caules e de folhas de A. humilis, em concentrações iguais a $16 \%$ $(\mathrm{p} / \mathrm{v})$, produziram efeitos inibitórios significativos na percentagem de germinação; nas demais concentrações, o efeito inibitório não foi constatado (Fig. 1). No caso da velocidade de germinação destas sementes, notou-se redução significativa causada pelos extratos de caules e folhas em concentrações iguais e superiores a $8 \%(\mathrm{p} / \mathrm{v})$ (Fig. 2).

As sementes de rabanete (Raphanus sativus) não sofreram inibição na capacidade germinativa em quaisquer concentrações dos extratos utilizados, exceto caules em 16\% (p/v) (Fig. 3). Entretanto, a velocidade de geminação dessas sementes foi reduzida significativamente com o uso de extratos de caules e folhas em concentrações iguais e superiores a $8 \%(\mathrm{p} / \mathrm{v}$ ) (Fig. 4).

Notou-se que nas concentrações onde não houve inibição da germinação, tanto em alface como em rabanete, ocorreu um visível escurecimento (necrose) de pequenas porções das sementes. Em algumas delas houve protrusão radicular, porém, a coifa mostrava-se totalmente oxidada, escurecida e, com o passar do tempo, as mesmas não cresceram mais, ocorrendo o amolecimento e a degradação de seus tecidos.

Para alface e rabanete, os extratos de caules e folhas de A.humilis causaram efeitos similares, tanto 


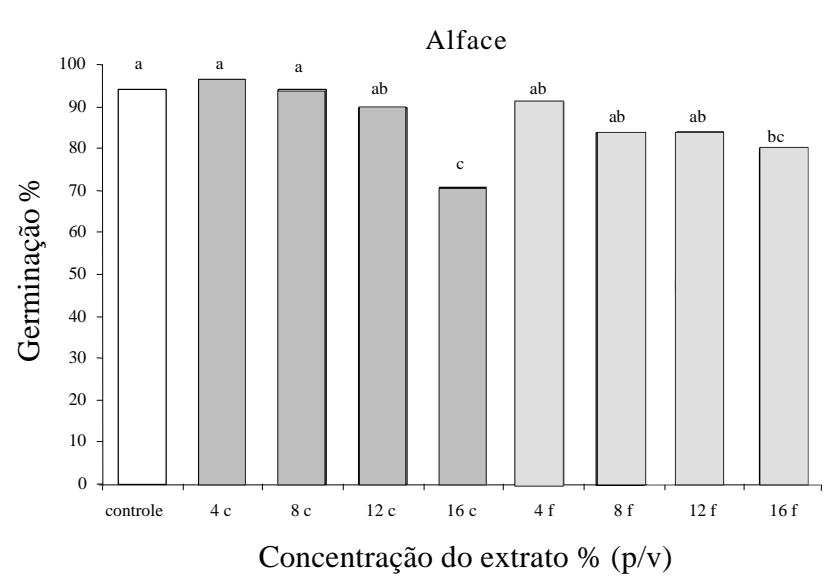

Figura 1. Percentagem de germinação de sementes de Lactuca sativa $\mathrm{L}$. sob o efeito de diferentes concentrações dos extratos aquosos de caules (c) e folhas (f) de Andira humilis Mart. ex Benth. Letras iguais indicam que os valores não diferem significativamente entre si a $5 \%$ de probabilidade, pelo teste de Tukey.

na germinabilidade como na velocidade de germinação, porém, as sementes de alface apresentaram maior redução da percentagem de germinação na presença de extrato de folhas a $16 \%(\mathrm{p} / \mathrm{v})$.

Os extratos aquosos de caules e folhas de A. humilis, em todas as concentrações, reduziram em uma relação dose dependente, o desenvolvimento de plântulas de alface (Fig. 5). As plântulas de rabanete sofreram inibição significativa do crescimento na presença de extratos de caules, porém, os extratos de folhas testados não inibiram seu crescimento (Fig. 6).

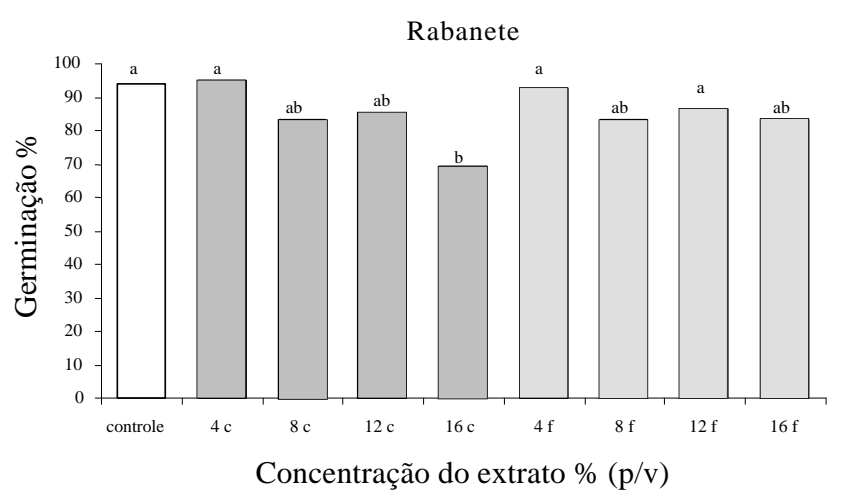

Figura 3. Percentagem de germinação de sementes de Raphanus sativus L. sob o efeito de diferentes concentrações dos extratos aquosos de caules (c) e folhas (f) de Andira humilis Mart. ex Benth. Letras iguais indicam que os valores não diferem significativamente entre si a $5 \%$ de probabilidade, pelo teste de Tukey.

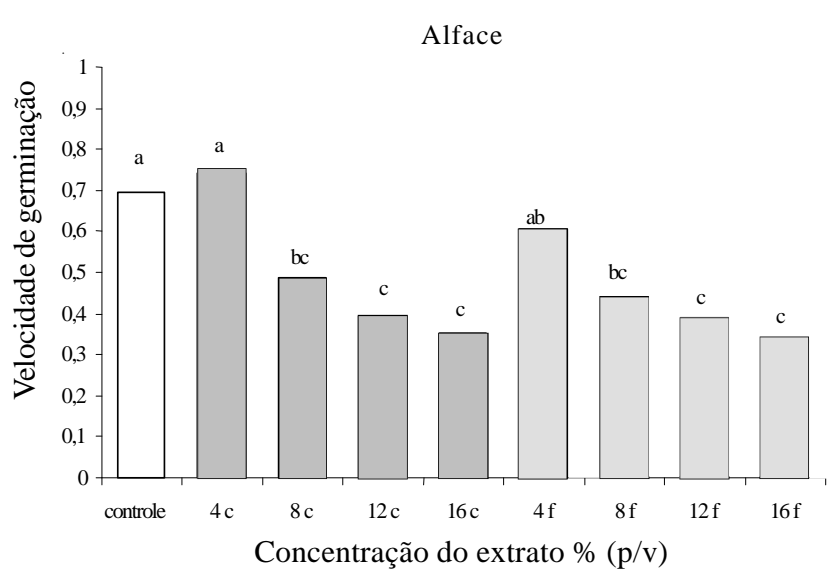

Figura 2. Velocidade de germinação $\left(\operatorname{dias}^{-1}\right)$ de sementes de Lactuca sativa L. sob o efeito de diferentes concentrações dos extratos aquosos de caules (c) e folhas (f) de Andira humilis Mart. ex Benth. Letras iguais indicam que os valores não diferem significativamente entre si a $5 \%$ de probabilidade, pelo teste de Tukey.

Observou-se que as plântulas de alface e de rabanete afetadas apresentaram os hipocótilos de tamanho reduzido, coifas radiculares oxidadas, escurecidas, raízes primárias prejudicadas e coloração escurecida dos cotilédones e hipocótilos.

A mortalidade de plântulas foi observada nos extratos em concentração de $12 \%(\mathrm{p} / \mathrm{v})$. Extratos de caules de $A$. humilis nessa concentração ocasionaram a morte de nove plântulas de alface e de oito plântulas de rabanete em seus respectivos testes de crescimento. Os extratos de folhas ocasionaram a morte de nove plântulas de alface. As plântulas de rabanete mostra-

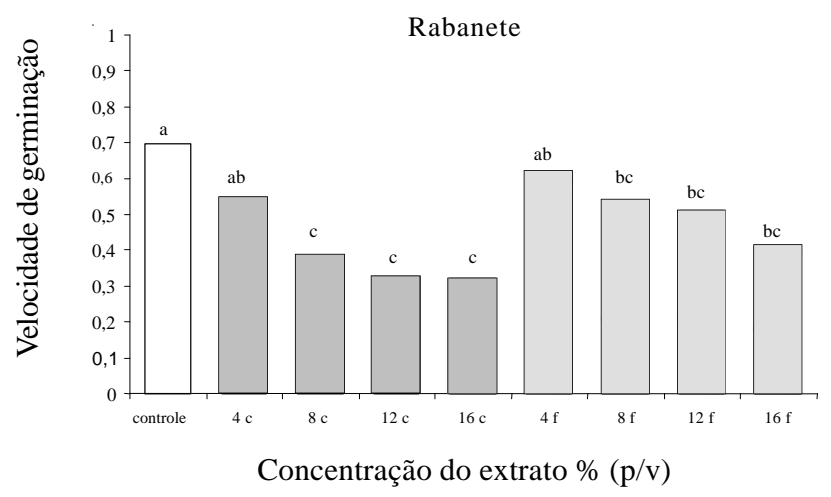

Figura 4. Velocidade de germinação $\left(\operatorname{dias}^{-1}\right)$ de sementes de Raphanus sativus L. sob o efeito de diferentes concentrações dos extratos aquosos de caules (c) e folhas (f) de Andira humilis Mart. ex Benth. Letras iguais indicam que os valores não diferem significativamente entre si a $5 \%$ de probabilidade, pelo teste de Tukey. 


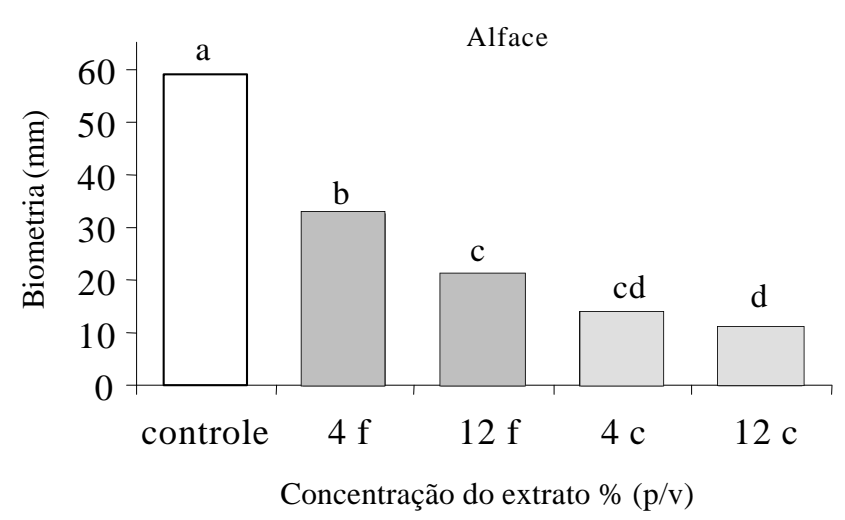

Figura 5. Comprimento das plântulas de Lactuca sativa L. sob o efeito de diferentes concentrações dos extratos aquosos de caules (c) e folhas (f) de Andira humilis Mart. ex Benth. Letras iguais indicam que os valores não diferem significativamente entre si a $5 \%$ de probabilidade, pelo teste de Tukey.

ram-se mais resistentes ao extrato de folhas, não sendo observadas plântulas mortas.

Observou-se que em sementes e plântulas de alface e de rabanete afetadas pelos extratos de A. humilis, não houve regeneração dos tecidos afetados. Do mesmo modo, Medeiros \& Lucchesi (1993) demonstraram que extratos aquosos de ervilhaca (Vicia sativa L.) exerceram forte influência negativa sobre a germinação de sementes de alface, sendo que, nas concentrações mais elevadas, houve oxidação dos tecidos das sementes, que sofreram rápida decomposição e, por fim, morreram.

Outro aspecto a ser mencionado, é que o efeito alelopático foi mais evidente sobre a velocidade de germinação e sobre o comprimento das plântulas, do que na percentagem final de sementes germinadas.

Ferreira \& Aquila (2000) apontam que a germinação é menos sensível aos aleloquímicos do que o crescimento da plântula, pois as substâncias alelopáticas podem induzir o aparecimento de plântulas anormais, sendo a necrose da radícula um dos sintomas mais comuns.

$\mathrm{O}$ controle do $\mathrm{pH}$ e da concentração osmótica dos extratos brutos é fundamental, pois pode haver neles substâncias como açúcares, aminoácidos e

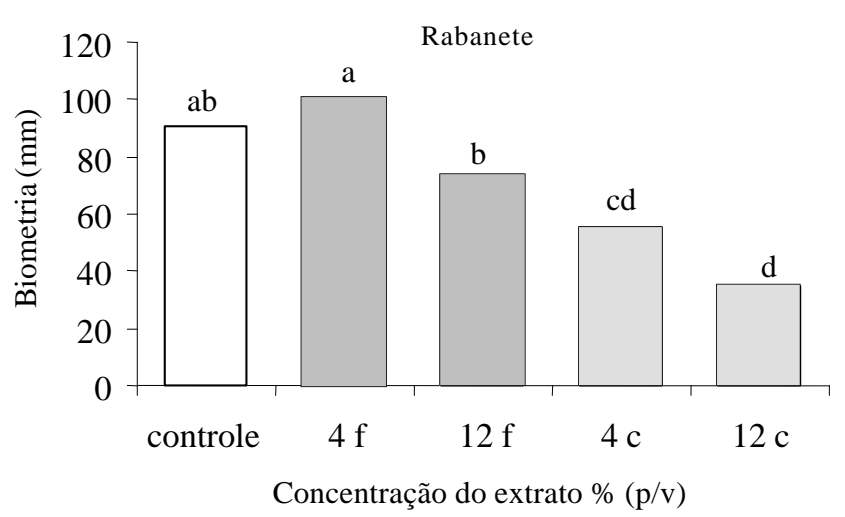

Figura 6. Comprimento das plântulas de Raphanus sativus L. sob o efeito de diferentes concentrações dos extratos aquosos de caules (c) e folhas (f) de Andira humilis Mart. ex Benth. Letras iguais indicam que os valores não diferem significativamente entre si a $5 \%$ de probabilidade, pelo teste de Tukey.

ácidos orgânicos que influem no $\mathrm{pH}$ e são osmoticamente ativos e essa atividade pode mascarar o efeito alelopático (Ferreira \& Aquila 2000). Dessa forma, foram medidos tais fatores físico-químicos nos extratos aquosos de caules e folhas de A. humilis (Tab. 1).

Na literatura, as informações disponíveis sobre os efeitos do $\mathrm{pH}$ sobre a germinação de sementes e o desenvolvimento de plântulas são basicamente referentes às espécies de regiões temperadas. De qualquer modo, esses dados indicam que tanto a germinação como o desenvolvimento são afetados negativamente, em condições de extrema acidez ou extrema alcalinidade (Souza Filho et al. 1996).

As concentrações molares encontradas nos extratos brutos de caules e folhas de A. humilis foram convertidas em valores de potenciais osmóticos. Com os dados de potenciais osmóticos obtidos foram feitos os testes de germinação de sementes e crescimento de plântulas de alface e de rabanete em solução de PEG 6000, nas concentrações molares e respectivos potenciais osmóticos equivalentes. Assim, pode-se afirmar que os extratos aquosos de caules e folhas de A. humilis utilizados no presente trabalho não foram osmoticamente ativos.

Tabela 1. Características físico-químicas e rendimento dos extratos aquosos de caules e folhas de Andira humilis de maior concentração, $16 \%$ (p/v), utilizados nos bioensaios para a verificação de atividade alelopática.

\begin{tabular}{ccccr}
\hline Extratos aquosos & $\mathrm{pH}$ & $\begin{array}{c}\text { Concentração molar } \\
(\mathrm{mOsm})\end{array}$ & $\begin{array}{c}\text { Potencial osmótico } \\
(\mathrm{MPa})\end{array}$ & $\begin{array}{c}\text { Rendimento } \\
\left(\mathrm{mg}^{-\mathrm{mL}^{-1}}\right)\end{array}$ \\
\hline Folhas & 5,45 & 12 & 0,030 & 13,80 \\
Caules & 5,39 & 15 & 0,038 & 8,61 \\
\hline
\end{tabular}


Após a investigação desses fatores, fortalece-se a idéia de que as alterações registradas na germinação e no crescimento de alface e rabanete são causadas por substâncias alelopáticas presentes nos extratos de Andira humilis.

Testes preliminares elaborados no presente trabalho sugerem que as substâncias presentes nas folhas de A. humilis, causadoras dos efeitos inibitórios na germinação de sementes e no crescimento de plântulas de alface, pertencem à classe dos taninos. Futuros experimentos envolvendo métodos modernos de extração, isolamento e purificação poderão contribuir para o conhecimento mais acurado dos compostos secundários presentes como agentes alelopáticos em $A$. humilis.

Rizzini (1970) estudou a inibição de germinação ocasionada por embriões de A. humilis. A potência dos inibidores aí presentes foi comparável à do ácido salicílico, da cumarina, da mimosina e do ácido cinâmico. Os inibidores também podem ser encontrados no mesocarpo e na planta adulta dessa espécie, sendo que, mesmo após oito meses de armazenamento dos restos de mesocarpo, ao ar, forte atividade inibitória foi observada.

Com os resultados do presente trabalho pode-se concluir que as alterações na germinação e no crescimento de alface e rabanete são ocasionadas pelo potencial alelopático de Andira humilis.

\section{Referências bibliográficas}

Almeida, S.P.; Proença, C.E.B.; Sano, S.M. \& Ribeiro, J.F. 1998. Cerrado: espécies vegetais úteis. EMBRAPACPAC, xii, Planaltina.

Benincasa, M.M.P. 1988. Análise de crescimento de plantas. FUNEP, Jaboticabal.

Brasil. 1992. Ministério da Agricultura e Reforma Agrária. Regras para análise de sementes. SNDA/DNDV/CLAV, Brasília.

Delachiave, M.E.A.; Rodrigues, J.D. \& Ono, E.O. 1999. Efeitos alelopáticoa de Losna (Artemisia absinthium L.) na germinação de sementes de pepino, milho, feijão e tomate. Revista Brasileira de Sementes 21(2): 265-269.
Einhellig, F.A. 1995. Mechanism of action of allelochemicals in allelopathy. Pp. 96-116 In: Inderjit; K.M.N. Dakshini \& F.A. Einhellig. Allelopathy, organisms, process and aplications. American Chemical Society, Washington.

Ferreira, A.G. \& Aquila, M.E.A. 2000. Alelopatia: uma área emergente da ecofisiologia. Revista Brasileira de Fisiologia Vegetal 12(Edição especial): 175-204.

Ferri, M.G. 1969. Plantas do Brasil. Espécies do Cerrado. Editora Edgard Blücher Ltda., Edição da Universidade de São Paulo.

Handro, W. 1969. Contribuição ao estudo da unidade de dispersão e da plântula de Andira humilis Mart. ex Benth. (Leguminosae-Lotoideae). Anais da Academia Brasileira de Ciências 41(2): 286-287.

Harborne, J.B. 1993. Introduction to Ecological Biochemistry. Academic Press, London.

Inderjit \& Dakshini, K.M.N. 1995. Algal Allelopathy. The Botanical Review - The New York Botanical Garden 61(1): 28-44.

Labouriau, L.G. \& Valadares, M.B. 1976. On the germination of seeds of Calotropis procera. Anais da Academia Brasileira de Ciências 48: 174-186.

Medeiros, A.R.M. \& Lucchesi, A.A. 1993. Efeitos alelopáticos da ervilhaca (Vicea sativa L.) sobre a alface em testes de laboratório. Pesquisa Agropecuária Brasileira 28: 9-14.

Miró, C.P.; Ferreira, A.G. \& Aquila, M.E.A. 1998. Alelopatia de frutos de erva-mate (Ilex paraguariensis) no desenvolvimento do milho. Pesquisa Agropecuária Brasileira 33(8): 1261-1270.

Rice, E.L. 1979. Allelopathy. An Update. Botanical Review, 45: 15-109.

Rice, E.L. 1984. Allelopathy. Academic Press Inc., London.

Rizzini, C.T. 1970. Inibidores de germinação e crescimento em Andira humilis Benth. Anais da Academia Brasileira de Ciências 42(Suplemento): 329-366.

Souza Filho, A.P.S.; Rodrigues, L.R.A. \& Rodrigues, T.J.D. 1996. Efeitos de extratos aquosos de assa-peixe sobre a germinação de três espécies de braquiária. Planta Daninha 14(2): 93-101.

Vilela, F.A.; Doni Filho, L. \& Sequeira, E.L. 1991. Tabela de potencial osmótico em função da concentração de polietileno glicol 6000 e da temperatura. Pesquisa Agropecuária Brasileira 26: 1957-1968.

Waller, G.R. 1999. Introduction. In: F.A. Macias; J.C.G. Galindo; J.M.G. Molinillo \& H.G. Cutler (eds.). Recent advances in allelopathy. Cádiz, Servicio de Publicaciones, Univiversidad de Cádiz, v.1. 